\title{
Intravitreal ranibizumab injection combined trabeculectomy versus Ahmed valve surgery in the treatment of neovascular glaucoma: assessment of efficacy and complications
}

\author{
Lan Liu', Yongfeng $\mathrm{Xu}^{2}$, Zhu Huang ${ }^{1}$ and Xiaoyu Wang ${ }^{1 *}$
}

\begin{abstract}
Background: Researches have shown anti-vascular endothelial growth factor (VEGF) agent is effective in treating neovascular eye diseases. The purpose of this study is to evaluate the efficacy and safety of intravitreal ranibizumab (IVR) injection combined trabeculectomy in the treatment of neovascular glaucoma (NVG), and compared it with Ahmed valve surgery.

Methods: Thirty-six NVG patients (37 eyes) from the First Affiliated Hospital of Zhejiang medical college, between January 1, 2014 and January 31, 2015, were included in this prospective, interventional clinical study. Eighteen NVG eyes were given IVR injection one week before trabeculectomy. Ahmed valve implantation surgery was performed in nineteen eyes. Ocular pain, best corrected visual acuity (BCVA), intraocular pressure (IOP) and surgical complications were evaluated before and after the surgery.

Results: IOP was significantly decreased following IVR injection combined trabeculectomy treatment (baseline $57.1 \pm 8$. $9 \mathrm{mmHg}$; week 1, $15.2 \pm 4.3 \mathrm{mmHg} p=0.000$; month 1, $16.9 \pm 2.1 \mathrm{mmHg} p=0.000$; month 3, $20.3 \pm 7.7 \mathrm{mmHg} p=0.000$; month $6,19.7 \pm 7.3 \mathrm{mmHg} p=0.000$ ). There was a significant, though modest, BCVA improvement in sighted eyes of IVR group (baseline $2.42 \pm 0.68, \mathrm{~W} 11.80 \pm 0.91, P=0.013 ; \mathrm{M} 11.77 \pm 0.93, p=0.011$ ). IVR injection combined trabeculectomy had less postoperative complications and lower failure ratio than Ahmed surgery (IVR 5.6\%, Ahmed $31.6 \%$ ).

Conclusions: The study revealed that IVR injection combined trabeculectomy was an effective and safe treatment for NVG. Compared with Ahmed surgery, IVR injection combined trabeculectomy had less complications and higher success ratio. (Chinese Clinical Registry, TRN ChiCTR-OPN-16008147, 3/24/2016, retrospectively registered)
\end{abstract}

Keywords: Neovascular glaucoma (NVG), Ranibizumab, Vascular endothelial growth factor (VEGF), Trabeculectomy, Ahmed valve surgery

\footnotetext{
* Correspondence: you2000xiang@sina.cn

1Department of Ophthalmology, the First Affiliated Hospital, College of

Medicine, Zhejiang University, 79\# Qingchun Road, Hangzhou, People's

Republic of China

Full list of author information is available at the end of the article
} 


\section{Background}

Neovascular glaucoma (NVG) is an intractable glaucoma secondary to the neovascularization of the iris and the anterior chamber angle. It is caused by ischemia and hypoxia of the retina in ocular ischemic diseases like proliferative diabetic retinopathy (PDR), central retinal vein occlusion (CRVO), etc. NVG is a serious ocular disorder with poor prognosis $[1,2]$. The management of NVG is still difficult. Conventional treatments including filtering surgery, cyclophotocoagulation, cryotherapy, aqueous drainage device, panretinal photocoagulation may still have a high risk of failure to control the intraocular pressure (IOP) and prevent deterioration of the disease [1-3].

Vascular endothelial growth factor (VEGF), a protein induced by hypoxia and ischemia, is an important regulator in angiogenesis and inflammation responses [4]. VEGF was found highly expressed in neovascular membranes and ocular fluids of neovascular ocular diseases such as PDR, CRVO and also NVG $[5,6]$. Therefore, VEGF inhibitors were effective in treating neovascular eye diseases. Ranibizumab (Lucentis), the Fab fragment of recombinant humanized IgG1kmurine monoclonal antibody against VEGF-A, was approved for the treatment of ocular neovascular diseases such as wet agerelated macular degeneration [7, 8]. The utilization of ranivizumab has been expanded to treat many diseases with macular edema such as PDR, CRVO and NVG in recent years $[9,10]$. There are several studies about bevacizumab, another anti-VEGF agent off-label used in ocular neovascular diseases, which has served as an effective medicine in treating NVG [11-13]. But clinical trials about the efficacy and safety of the ranibizumab in treating NVG are relatively rare.

Our study was designed to test the efficacy of intravitreal ranibizumab (IVR) injection combined with trabeculectomy with mitomycin $\mathrm{C}$ (MMC) on patients with NVG. We also compared its efficacy and safety with the conventional treatment, Ahmed valve surgery, to evaluate advantages and disadvantages of these two therapies separately.

\section{Methods}

\section{Patients and inclusion criteria}

The study was a prospective interventional study including 36 patients with 37 NVG eyes. Randomized placebocontrolled design was not conducted because the poor prognosis of NVG left no room for ethical randomization. NVG patients were treated in the ophthalmology department of the First Affiliated Hospital of Zhejiang medical college, Zhejiang University, Hangzhou, China, between January 1, 2014 and January 31, 2015. The study was approved by the Ethics Committee of the First Affiliated Hospital of Zhejiang University and it was performed in accordance with the tenets of the Declaration of Helsinki.
All patients were aware of their therapy. An informed consent form was signed by every patient.

Patients were included in the study based on the following criteria: (i) age > 20 years; (ii) diagnosed as NVG with rubeosis; (iii) IOP $>21 \mathrm{mmHg}$ with the maximum use of anti-glaucoma drugs. Exclusion criteria included: (i) active ocular infection; (ii) previous glaucoma filtering surgery; (iii) previous anti-VEGF treatment; (iv) any contraindication of intraocular injection or surgery, such as high risk of bleeding, pregnancy, and infection, et al.

NVG patients received one of two types of treatment: IVR injection and subsequent trabeculectomy with MMC, or Ahmed valve implantation surgery. Main medical history and previous treatments were recorded.

\section{IVR injection and surgical techniques}

All surgeries and intravitreal injections were performed by Dr. Xiaoyu Wang and Dr. Lan Liu. Eighteen eyes with NVG received IVR injection under topical anesthesia in the aseptic condition of an operating room. $0.5 \mathrm{mg}$ (0.05 ml) Ranibizumab was injected through the pars plana with a $25 \mathrm{G}$ needle. The patients were given topical antibiotics and previous antiglaucoma medicines for 1 week after injection. The surgery of trabeculectomy with MMC was performed 1 week later. The globe was pulled inferiorly by a traction suture. The conjunctival incision was made along the limbus to create a fornixbased conjunctival flap in the superotemporal quadrant. A half thick $4 \mathrm{~mm} \times 4 \mathrm{~mm}$ square scleral flap was made. MMC $(0.4 \mathrm{mg} / \mathrm{ml})$ soaked sponge was placed under the scleral flap for 1 to $2 \mathrm{~min}$. Then the area was irrigated with plenty of saline. Trabecular meshwork $(1 \times 1.5 \mathrm{~mm})$ was cut and the peripheral iridectomy $(1 \times 1 \mathrm{~mm})$ was preformed. The scleral flap was closed with two 10-0 nylon sutures at its corners. The conjunctiva was sutured with 8-0 vicryl sutures.

Ahmed valve implantation surgery was performed on nineteen NVG eyes and the procedure was described as follows. A fornix-based conjunctival and Tenon's flap was created in the superotemperal quadrant. The Ahmed valve implantation (Model FP7, New World Medical, Inc.) was inserted into the Tenon's capsule and fixed on the sclera $8 \mathrm{~mm}$ posterior to the limbus with 8 0 sutures. A $4 \mathrm{~mm} \times 4 \mathrm{~mm}$ square scleral flap was made, a corneoscleral track was made by a 23-gauge needle and the tube was inserted into the anterior chamber through the scleral flap. The tube was fixed to the episclera with 8-0 sutures. Topical eyedrops of antibiotics and steroids were used in every patient for two weeks.

\section{Outcome measurement and follow-up}

Pain of the patients was assessed and recorded by numerical rating scale (NRS), ranging from 0 (no pain) to 10 (worst imaginable pain). Best corrected visual acuity 
(BCVA), IOP (Goldmann applanation tonometer), angle status and full ophthalmic examination were taken before and after the surgery. BCVA was recorded using logMAR equivalent, and counting fingers was assigned value 2, hand movement was assigned 3. The new vessels of iris were observed by slip lamp. Surgical complications and postoperative anti-glaucoma medications were also recorded. The patients were followed up for at least 6 month and the IOP and BCVA were recorded on day 1, week 1 , then monthly after the operation. The staff members performing the NRS, BCVA and IOP assessment were not involved in implementing the surgeries.

The efficacy of the treatment was evaluated by the success of the surgery. Complete success was defined as IOP $\geq 6 \mathrm{mmHg}$ and $\leq 21 \mathrm{mmHg}$ without any antiglaucoma medications or further glaucoma surgery, and without loss of light perception. Partial success was defined as IOP $<21 \mathrm{mmHg}$ with topical anti-glaucoma medicines. Surgical failure was defined as $I O P \geq$ $21 \mathrm{mmHg}$ even with anti-glaucoma medicines, or additional surgical treatment was needed to control IOP, or loss of light perception.

\section{Statistical analysis}

Statistical analysis was conducted using the software SPSS 10.0 (SPSS, Inc. Chicago, IL). Independent and paired Student t-test was used to assess differences between groups. Results were presented as mean \pm standard deviation (SD). $P<0.05$ was considered statistically significant.

\section{Results}

\section{Baseline characteristics}

Thirty-six NVG patients (37 eyes) were included in the study. Eighteen NVG eyes underwent IVR injection and subsequent trabeculectomy (IVR group). Nineteen eyes underwent Ahmed valve implantation surgery (Ahmed group). The patients' demographics and basic characteristics were summarized in Table 1 . There were no differences in the gender and age between the two groups. Of all 37 NVG eyes, 14 (37.8\%) were caused by PDR, 18 (48.6 \%) by CRVO, 1 (2.7 \%) by branch retinal vein occlusion (BRVO), 1 (2.7 \%) by ischemic optic neuropathy, and $3(8.1 \%)$ were after the intraocular surgery. There were no differences among the causes between two groups. The baseline IOP was $57.1 \pm 8.9 \mathrm{mmHg}$ in the IVR group and $49.8 \pm 11.8 \mathrm{mmHg}$ in the Ahmed group. Baseline BCVA of sighted eyes was $2.42 \pm 0.68$ in the IVR group and $2.51 \pm 0.84$ in the Ahmed group. No differences were found in baseline IOP $(p=0.12)$ and BCVA $(p=0.68)$ between the two groups. Sixteen eyes $(88.9 \%)$ in the IVR group and 17 eyes $(89.5 \%)$ in the Ahmed group were given retinal photocoagulation before the operation, and no differences were found
Table 1 Baseline characteristics of included patients

\begin{tabular}{|c|c|c|c|}
\hline & $\begin{array}{l}\text { IVR and trabeculectomy } \\
\text { with MMC }(n=18)\end{array}$ & $\begin{array}{l}\text { Ahmed valve } \\
\text { surgery }(n=19)\end{array}$ & $P$ value \\
\hline Age (y) & $62.3 \pm 10.8$ & $56.7 \pm 13.6$ & 0.54 \\
\hline \multicolumn{4}{|l|}{ Sex } \\
\hline $\begin{array}{l}\text { Male } \\
\text { Female }\end{array}$ & $\begin{array}{l}11(61.1 \%) \\
7(38.9 \%)\end{array}$ & $\begin{array}{l}10(52.6 \%) \\
9(47.4 \%)\end{array}$ & 0.74 \\
\hline \multicolumn{4}{|l|}{ Systemic diseases } \\
\hline $\begin{array}{l}\text { Hypertention } \\
\text { Diabetes mellitus }\end{array}$ & $\begin{array}{l}11(61.1 \%) \\
6(33.3 \%)\end{array}$ & $\begin{array}{l}12(63.2 \%) \\
9(47.4 \%)\end{array}$ & \\
\hline \multicolumn{4}{|l|}{ Causes of NVG } \\
\hline $\begin{array}{l}\text { PDR } \\
\text { CRVO }\end{array}$ & $\begin{array}{l}6(33.3 \%) \\
10(55.6 \%)\end{array}$ & $\begin{array}{l}8(42.1 \%) \\
8(42.1 \%)\end{array}$ & \\
\hline BRVO & & $1(5.3 \%)$ & \\
\hline $\begin{array}{l}\text { After intraocular } \\
\text { surgery }\end{array}$ & $2(11.1 \%)$ & 1(5.3\%) & \\
\hline $\begin{array}{l}\text { Ischemic optic } \\
\text { neuropathy }\end{array}$ & & $1(5.3 \%)$ & \\
\hline \multicolumn{4}{|l|}{ Lens status } \\
\hline $\begin{array}{l}\text { Phakic } \\
\text { Intraocular lens }\end{array}$ & $\begin{array}{l}16(88.8 \%) \\
2(11.1 \%)\end{array}$ & $\begin{array}{l}13(68.4 \%) \\
6(31.6 \%)\end{array}$ & \\
\hline $\begin{array}{l}\text { Baseline IOP } \\
(\mathrm{mmHg})\end{array}$ & $57.1 \pm 8.88$ & $49.8 \pm 11.8$ & 0.12 \\
\hline \multicolumn{4}{|l|}{ BCVA (logMAR) } \\
\hline $\begin{array}{l}\text { NLP } \\
\text { LP } \\
\text { Others }\end{array}$ & $\begin{array}{l}3 \\
2 \\
2.42 \pm 0.68\end{array}$ & $\begin{array}{l}3 \\
3 \\
2.51 \pm 0.84\end{array}$ & 0.68 \\
\hline Pain grade (NRS) & $6.44 \pm 0.78$ & $5.68 \pm 1.00$ & 0.33 \\
\hline
\end{tabular}

Abbreviations: NVG neovascular glaucoma, $P D R$ proliferative diabetic retinopathy, CRVO central retinal vein occlusion, $B R V O$ branch retinal vein occlusion, IOP intraocular pressure, BCVA best corrected visual acuity, NLP no light perception, $L P$ light perception, IVR intravitreal ranibizumab, $M M C$ mitomycin C

between the two groups. Two eyes in the IVR group and 3 eyes in the Ahmed group were given additional retinal photocoagulation after the operation to prevent deterioration due to the diseases. There were 3 patients ( 1 in the IVR group, 2 in the Ahmed group) who experienced enucleation in month 3 due to the uncontrolled high IOP and unbearable eye pain, and were lost to follow-up.

\section{Rubeosis regression and pain relief}

Rubeosis was found in all 37 NVG eyes (100\%) and hyphema in 3 patients $(8.1 \%)$ before treatment. In the IVR group, the new vessels of the iris apparently regressed in all 18 eyes after the IVR injection (Fig. 1). The eye pain (NRS score) was significantly relieved one week after trabeculectomy (before surgery $6.4 \pm 0.8$; one week $2.2 \pm 0.5 p=0.000$ ), and had almost disappeared one month later $(0.3 \pm 0.5, p=0.000)$. In the Ahmed group, the pain was also significantly decreased at one week (5.7 \pm 1.0 ; one week, $2.6 \pm 0.96, p=0.000)$ and almost vanished one month later $(0.5 \pm 0.7, p=0.000$, Table 2). The NRS score remained low in both groups at 


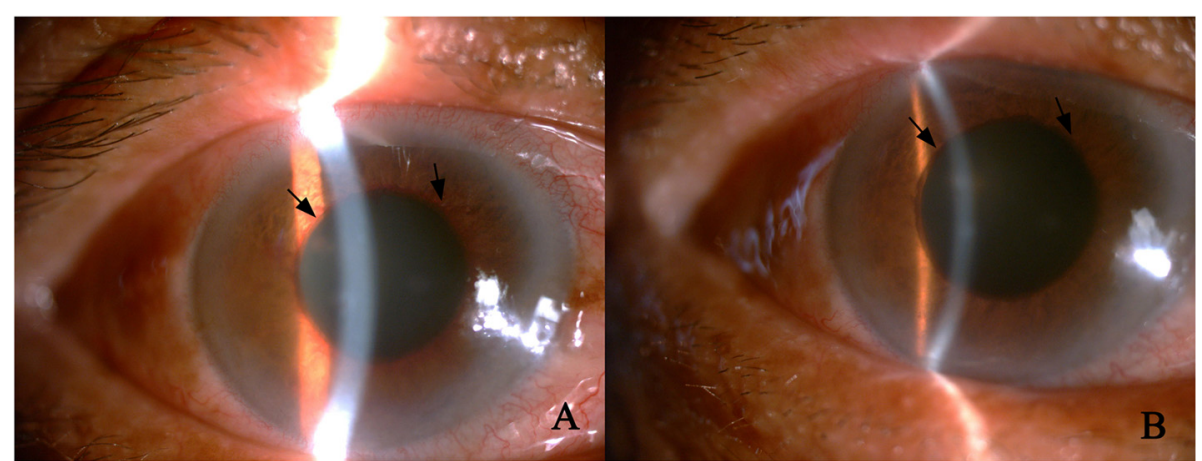

Fig. 1 Anterior segment photography of a neovascular glaucoma patient before and after intravitreal ranibizumab injection (IVR). a. Massive new vessels (black arrows) were seen on the iris around the pupil before IVR. $\mathbf{b}$. New vessels were regressed (black arrows) three days after IVR from the same patient of $\mathrm{A}$

month 3 and month 6 , except 1 patient in IVR group, 2 in Ahmed group had increased NRS score (IVR 7, Ahmed 8) owing to the uncontrolled IOP.

\section{IOP}

In the IVR group, IOP was significantly decreased (week $1,15.2 \pm 4.3 \mathrm{mmHg} p=0.000$; month $1,16.9 \pm 2.1 \mathrm{mmHg}$ $p=0.000$; month 3, $20.3 \pm 7.7 \mathrm{mmHg} p=0.000$; month 6, $19.7 \pm 7.3 \mathrm{mmHg} p=0.000)$ after trabeculectomy compared with the baseline IOP $(57.1 \pm 8.9 \mathrm{mmHg})$. But IOP was only slightly lowered after IVR injection (55.9 \pm $6.9 \mathrm{mmHg}, p=0.154)$. There was also a significant drop of IOP in the NVG eyes of the Ahmed group (W1 $12.8 \pm$ $8.7 \mathrm{mmHg} p=0.000$, M1 $19.7 \pm 4.5 \mathrm{mmHg} p=0.000$, M3 $24.9 \pm 14.2 \mathrm{mmHg} p=0.000$, M6 $22.8 \pm 11.2 \mathrm{mmHg}$ $p=0.000$ ) (Fig. 2.). Results showed that IOP was significantly lower in the IVR group than that in the Ahmed group at month $1(P=0.021)$. There were no differences of IOP between the two groups at week $1(P=0.302)$, month $3(P=0.225)$ and month $6(P=0.324)$.

\section{BCVA}

Visual acuity was relatively low in all NVG patients. Mean BCVA of sighted eyes $(n=26)$ was $2.46 \pm 0.75$

Table 2 NRS scores and BCVA of neovascular glaucoma patients

\begin{tabular}{lll}
\hline & IVR group $(n=18)$ & Ahmed group $(n=19)$ \\
\hline NRS scores & & \\
Before surgery & $6.4 \pm 0.8$ & $5.7 \pm 1.0$ \\
1 week after surgery & $2.2 \pm 0.5$ & $2.6 \pm 0.96$ \\
1 month after surgery & $0.3 \pm 0.5$ & $0.5 \pm 0.7$ \\
BCVA (sighted eyes) & & \\
Before surgery & $2.42 \pm 0.68$ & $2.51 \pm 0.84$ \\
1 week after surgery & $1.80 \pm 0.91$ & $1.92 \pm 1.24$ \\
1 month after surgery & $1.77 \pm 0.93$ & $2.53 \pm 0.85$ \\
\hline
\end{tabular}

Abbreviations: IVR intravitreal ranibizumab, NRS numerical rating scale, $B C V A$ best corrected visual acuity
(IVR $2.42 \pm 0.68$, Ahmed $2.51 \pm 0.84$ ), and 5 eyes showed light perception (LP), 6 had no light perception (NLP) (Table 1). Results showed that there was a significant BCVA improvement at week 1 and month 1 in the IVR group (W1 $1.80 \pm 0.91, P=0.013 ;$ M1 $1.77 \pm 0.93, p=$ 0.011) compared with the baseline, though the improvement was relatively modest. BCVA was not significantly increased in the Ahmed group (W1 $1.92 \pm 1.24, P=$ 0.156 ; M1, $2.53 \pm 0.85, p=0.252$, Table 2). Visual acuity of all NVG patients in both groups maintained stable after month 1 , except 1 patient in the IVR group and 2 in the Ahmed group who lost light perception due to the uncontrolled IOP at month 3.

\section{Complications}

There were no intraoperative complications in either the IVR or the Ahmed group. There were apparently more postoperative complications in the Ahmed group than in the IVR groups (Table 3), especially in the early postoperative period (within two weeks of the surgery). Six eyes were found with low IOP (hypotony, IOP $\leq 5 \mathrm{mmHg}$ ), 2 eyes with shallow anterior chamber, 1 eye with no anterior chamber which needed additional surgery, and 1 eye with hyphema and 1 eye with exudative inflammation at week 1 in the Ahmed group. There were no early complications in the IVR group. In the late postoperative period (after two weeks), 3 eyes (16.7 \%) with complications (hyphema, vitreous hemorrhage and high IOP) were found in the IVR group. There were obviously more complications in the Ahmed group (8 eyes, $42.1 \%$ ).

In the IVR group, 11 eyes (61.1\%) were maintained IOP $<21 \mathrm{mmHg}$ without anti-glaucoma medications (complete success), 6 eyes (33.3\%) maintained IOP < $21 \mathrm{mmHg}$ with medications (partial success), 1 eye (5.6\%) failed to control IOP even with anti-glaucoma medications. In the Ahmed group 11 eyes (57.9\%) had complete success, 2 eyes (10.5\%) partial success and 6 eyes $(31.6 \%)$ failed. 
Mean IOP of NVG eyes after treatment of IVR combined trabeculectomy

and Ahmed valve surgery

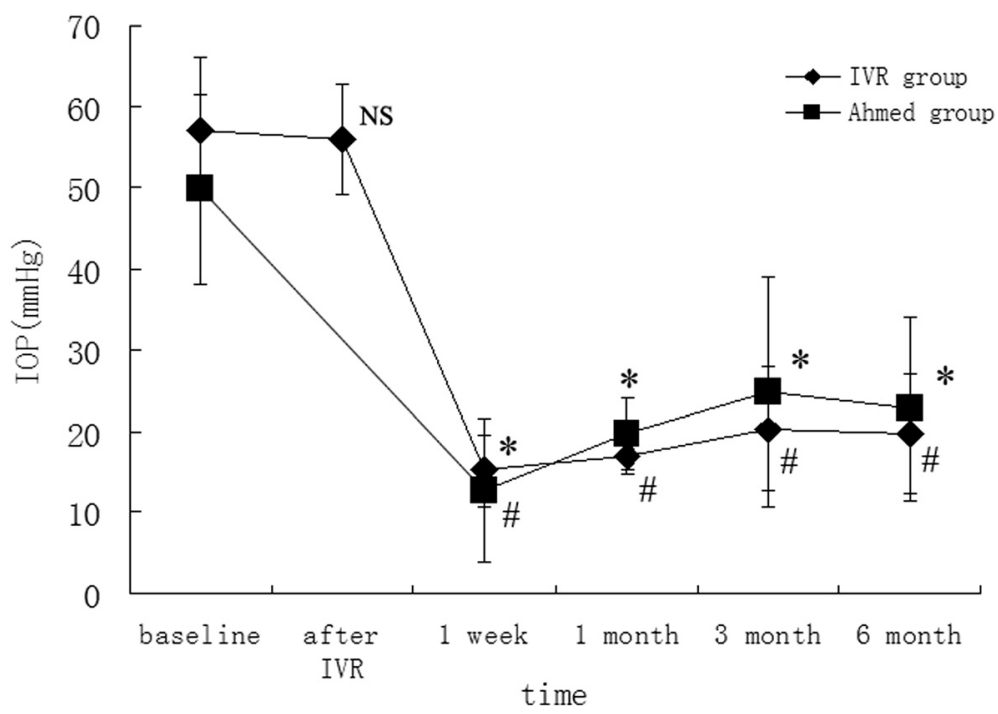

Fig. 2 Mean intraocular pressure (IOP) before and after the surgery in intravitreal ranibizumab injection (IVR) group and Ahmed surgery (Ahmed) group. * $P<0.05$ compared with the baseline of IVR group, $\#, P<0.05$ compared with the baseline of Ahmed group. NS, $P>0.05$ compared with the baseline of IVR group

\section{Discussion}

NVG is a serious and refractory glaucoma with poor prognosis. There are no optimal treatments that would cure the disease. Conventional treatment would still fail due to the recurrence of neovascularization [14]. In our study, we evaluated the efficacy of IVR injection combined with trabeculectomy in treating NVG patients, and which we also compared with treatment of Ahmed valve surgery. Our results showed that IVR injection

Table 3 Intraoperative and postoperative complications

\begin{tabular}{lll}
\hline & IVR group $(n=18)$ & $\begin{array}{l}\text { Ahmed group } \\
(n=19)\end{array}$ \\
\hline intraoperative & 0 & 0 \\
Early postoperative $^{\mathrm{a}}$ & & \\
$\begin{array}{l}\text { Shallow or no anterior chamber } \\
\text { hypotony }\end{array}$ & 0 & $3(15.8 \%)$ \\
Hyphema & 0 & $6(31.6 \%)$ \\
Exudative inflammation & 0 & $1(5.3 \%)$ \\
subtotal & 0 & $1(5.3 \%)$ \\
Late postoperative & & $11(57.9 \%)$ \\
Hyphema & & \\
Vitreous hemorrhage & $1(5.5 \%)$ & 0 \\
endophthalmitis & $1(5.5 \%)$ & $2(10.5 \%)$ \\
Shallow or no anterior chamber & 0 & 0 \\
High IOP & 0 & $1(5.3 \%)$ \\
Tube occlusion by iris & $1(5.5 \%)$ & $3(15.8 \%)$ \\
subtotal & 0 & $2(10.5 \%)$ \\
total & $3(16.7 \%)$ & $8(42.1 \%)$ \\
\hline
\end{tabular}

aEarly postoperative: within two weeks after the surgery; ${ }^{b}$ Late postoperative: after two weeks of the surgery evidently reduced the new vessels of the iris, IVR combined trabeculectomy effectively relieved the ocular pain, controlled IOP, and partially improved BCVA. Compared with the Ahmed valve surgery, the IVR combined trabeculectomy treatment had less postoperative complications and lower failure ratios.

NVG is caused by the neovascularization and fibration of the anterior chamber angle and iris, and results in uncontrolled IOP and ocular pain. Proper management should include the treatment of the underlying disease and the high IOP $[2,15]$. Trabeculectomy was considered the most effective surgical procedure for reducing IOP in patients with primary open-angle glaucoma and primary angle-close glaucoma $[16,17]$. But the management of NVG is still highly challenging and controversial. Trabeculectomy alone had a high risk of failure to control IOP of NVG, due to the bleb adhesion by neovascularization in the anterior chamber angle [2]. Improper treatment would finally result in blindness and intractable ocular pain. In managing NVG, it is important to treat underlying causes in addition to the elevated IOP [15]. VEGF is the key angiogenic factor in the pathogenesis of neovascular ocular diseases such as NVG [18]. Inhibition of VEGF also markedly reduced the fibroblast proliferation and scar formation after glaucoma filtration surgery $[19,20]$. Therefore, anti-VEGF antibody served as a useful adjunctive to the therapy of NVG via its anti-angiogenic and anti-fibrotic properties [21]. In our study, we treated 18 NVG eyes with antiVEGF drugs (ranibizumab) before the trabeculectomy 
with MMC. We found that IVR injection could significantly decrease the iris neovascularization and partly lower IOP. Since neovascularization was the main cause of NVG, IVR injection might provide chances to increase the success probability of the subsequent antiglaucoma surgery.

Recent studies have shown outstanding efficacy of anti-VEGF agents (bevacizumab, ranibizumab) in treating neovascular eye diseases, such as age-related macular degeneration [7, 8]. Several studies have shown that bevacizumab injection was a useful adjuvant for the treatment of NVG $[11,12]$. Intraocular injection of bevacizumab could significantly reduce the new vessels in the anterior chamber angle, lower IOP and decrease the aqueous VEGF concentration [22, 23]. The study by Klettner and Roider revealed ranibizumab was more efficient than bevacizumab in neutralizing VEGF in vitro [24]. And due to the off-label use of bevacizumab in eye diseases, ranibizumab (Lucentis) should be more suitable in treating NVG. There were no randomized controlled trials (RCTs) using anti-VEGF agents for the treatment of NVG [25], while there are a few studies about uses of ranibizumab in NVG. Artilces by Elmekawey and Kitnarong $[26,27]$ showed that intracameral or intravitreous injection of ranibizumab combined trabeculectomy effectively controlled IOP of NVG. A study by Li et al. [28] found that IVR combined vitrectomy, lensectomy, retinal photocoagulatin and trabeculectomy could control IOP and improve BCVA for NVG patients with vitreous hemorrhage. Luke et al [29] used IVR alone and showed, with repeated injections, it was beneficial for treating NVG. Desai et al [30] found that intravitreal injection of ranibizumab was an effective adjunctive treatment to Ahmed tube surgery in open-angle glaucoma. In our study, we conducted intravitreal injection of ranibizumab before trabeculectomy, and compared its efficacy and complications with the conventional Ahmed valve surgery. Our results revealed that the treatment of IVR injection combined trabeculectomy induced apparent regression of iris new vessels, significantly relieved eye pain, lowered IOP and partially improved BCVA in NVG patients. The high ratio of complete and partial success supported the efficacy of IVR injection combined trabeculectomy in treatment of NVG.

A Glaucoma drainage device (such as Ahmed valve implantation) was usually chosen as a common option to treat the secondary glaucoma in complex cases like NVG [2]. We compared the efficacy and complications of IVR + trabeculectomy treatment with the treatment of Ahmed valve surgery on NVG in our study. Our results showed that while Ahmed valve surgery also significantly relieved the eye pain, lowered IOP and partially improved BCVA, compared with IVR injection with trabeculectomy, Ahmed valve surgery markedly increased the postoperative complications, especially in the early postoperative stage, such as shallow or no anterior chamber, hyphema and hypotony. These complications ultimately increased the failure probabilities of the Ahmed surgery. Results showed that there was lower failure ratio in the IVR group compared with the Ahmed group.

Overall our study showed that IVR combined trabeculectomy would be an effective and safe treatment for NVG. Further clinical trials with larger sample numbers are needed to provide more evidence to define this optimal treatment of NVG.

\section{Conclusions}

Our study demonstrated IVR injection combined trabeculectomy was an effective and safe treatment for NVG. Compared with Ahmed surgery, IVR injection combined trabeculectomy had less complications and higher success ratio.

\section{Abbreviations}

BCVA, Best corrected visual acuity; CRVO, central retinal vein occlusion; IOP, intraocular pressure; IVR, intravitreal ranibizumab; MMC, mitomycin C; NRS, numerical rating scale; NVG, Neovascular glaucoma; PDR, proliferative diabetic retinopathy; RCTs, randomized controlled trials; VEGF, Vascular endothelial growth factor.

\section{Acknowledgements}

We thank Yang Wang and Lingling Xiang for their help.

Funding

This study was funded by Education Project of Zhejiang Province Office (Y201328272) and Medical and Health Science Project of Zhejiang Province (2016KYB096).

\section{Availability of data and materials}

The data supporting our findings is contained within the manuscript, or others will be shared upon request.

\section{Authors' contributions}

LL participated in the design of the study, carried out the study and revised the manuscript and performed the statistical analyses. YX has participated in the design and the drafting of the manuscript. ZH participated in the design of the study, carried out the analysis including statistics. XW has participated in the study's coordination and has helped to draft the manuscript and has been involved in revising the manuscript carefully. All authors read and approved the final manuscript.

\section{Competing of interests}

All authors certify that they have no affiliations with or involvement in any organization or entity with any financial interest, or non-financial interest in the subject matter or materials discussed in this manuscript.

\section{Consent for publication}

The patient signed a consent form and agreed with his slitlamp photo to be published.

\section{Ethics approval and consent to participate}

The study was approved by Ethics Committee of the First Affiliated Hospital, College of Medicine, Zhejiang University (2013-272).

\section{Author details}

'Department of Ophthalmology, the First Affiliated Hospital, College of Medicine, Zhejiang University, 79\# Qingchun Road, Hangzhou, People's Republic of China. ${ }^{2}$ Department of Neurology, the Second Affiliated Hospital, School of Medicine, Zhejiang University, Hangzhou, People's Republic of China. 
Received: 27 October 2015 Accepted: 21 May 2016

\section{Published online: 26 May 2016}

\section{References}

1. Shazly TA, Latina MA. Neovascular glaucoma: etiology, diagnosis and prognosis. Semin Ophthalmol. 2009;24(2):113-21.

2. Hayreh SS. Neovascular glaucoma. Prog Retin Eye Res. 2007;26(5):470-85.

3. Kuang TM, Liu CJ, Chou CK, Hsu WM. Clinical experience in the management of neovascular glaucoma. J Chin Med Assoc. 2004;67(3):131-5.

4. Shweiki D, Itin A, Soffer D, Keshet E. Vascular endothelial growth factor induced by hypoxia may mediate hypoxia-initiated angiogenesis. Nature. 1992;359(6398):843-5.

5. Aiello LP, Avery RL, Arrigg PG, Keyt BA, Jampel HD, Shah ST, et al. Vascular endothelial growth factor in ocular fluid of patients with diabetic retinopathy and other retinal disorders. N Engl J Med. 1994;331(22):1480-7.

6. Tripathi RC, Li J, Tripathi BJ, Chalam KV, Adamis AP. Increased level of vascular endothelial growth factor in aqueous humor of patients with neovascular glaucoma. Ophthalmology. 1998;105(2):232-7.

7. Brown DM, Kaiser PK, Michels M, Soubrane G, Heier JS, Kim RY, et al. Ranibizumab versus verteporfin for neovascular age-related macular degeneration. N Engl J Med. 2006;355(14):1432-44

8. Rosenfeld PJ, Brown DM, Heier JS, Boyer DS, Kaiser PK, Chung CY, et al. Ranibizumab for neovascular age-related macular degeneration. N Engl J Med. 2006:355(14):1419-31.

9. Massin P, Bandello F, Garweg JG, Hansen LL, Harding SP, Larsen M, et al. Safety and efficacy of ranibizumab in diabetic macular edema (RESOLVE Study): a 12-month, randomized, controlled, double-masked, multicenter phase II study. Diabetes Care. 2010;33(11):2399-405.

10. Brown DM, Campochiaro PA, Singh RP, Li Z, Gray S, Saroj N, et al. Ranibizumab for macular edema following central retinal vein occlusion: six-month primary end point results of a phase III study. Ophthalmology. 2010;117(6):1124-33

11. Ehlers JP, Spirn MJ, Lam A, Sivalingam A, Samuel MA, Tasman W. Combination intravitreal bevacizumab/panretinal photocoagulation versus panretinal photocoagulation alone in the treatment of neovascular glaucoma. Retina. 2008;28(5):696-702.

12. Wakabayashi T, Oshima Y, Sakaguchi H, Ikuno Y, Miki A, Gomi F, et al. Intravitreal bevacizumab to treat iris neovascularization and neovascular glaucoma secondary to ischemic retinal diseases in 41 consecutive cases. Ophthalmology. 2008;115(9):1571-80.

13. Yazdani S, Hendi K, Pakravan M. Intravitreal bevacizumab (Avastin) injection for neovascular glaucoma. J Glaucoma. 2007;16(5):437-9.

14. SooHoo JR, Seibold LK, Kahook MY. Recent advances in the management of neovascular glaucoma. Semin Ophthalmol. 2013;28(3):165-72.

15. Sivak-Callcott JA, O'Day DM, Gass JD, Tsai JC. Evidence-based recommendations for the diagnosis and treatment of neovascular glaucoma. Ophthalmology. 2001;108(10):1767-76.

16. Rulli E, Biagioli E, Riva I, Gambirasio G, De Simone I, Floriani I, et al. Efficacy and safety of trabeculectomy vs nonpenetrating surgical procedures: a systematic review and meta-analysis. JAMA Ophthalmol. 2013;131(12):1573-82

17. Chen YH, Lu DW, Cheng JH, Chen JT, Chen CL. Trabeculectomy in patients with primary angle-closure glaucoma. J Glaucoma. 2009;18(9):679-83.

18. Gariano RF, Gardner TW. Retinal angiogenesis in development and disease. Nature. 2005:438(7070):960-6.

19. Li Z, Van Bergen T, Van de Veire S, Van de Vel I, Moreau H, Dewerchin M, et al. Inhibition of vascular endothelial growth factor reduces scar formation after glaucoma filtration surgery. Invest Ophthalmol Vis Sci. 2009;50(11): 5217-25.

20. Mathew R, Barton K. Anti-vascular endothelial growth factor therapy in glaucoma filtration surgery. Am J Ophthalmol. 2011;152(1):10-5.

21. Horsley MB, Kahook MY. Anti-VEGF therapy for glaucoma. Curr Opin Ophthalmol. 2010;21(2):112-7.

22. Avery RL. Regression of retinal and iris neovascularization after intravitreal bevacizumab (Avastin) treatment. Retina. 2006;26(3):352-4.

23. Grover S, Gupta S, Sharma R, Brar VS, Chalam KV. Intracameral bevacizumab effectively reduces aqueous vascular endothelial growth factor concentrations in neovascular glaucoma. Br J Ophthalmol. 2009:93(2):273-4.

24. Klettner A, Roider J, Klettner A, Roider J. Comparison of bevacizumab, ranibizumab, and pegaptanib in vitro: efficiency and possible additional pathways. Invest Ophthalmol Vis Sci. 2008;49(10):4523-7.
25. Simha A, Braganza A, Abraham L, Samuel P, Lindsley K. Anti-vascular endothelial growth factor for neovascular glaucoma. Cochrane Database Syst Rev. 2013;10:CD007920.

26. Elmekawey $\mathrm{H}$, Khafagy $\mathrm{A}$. Intracameral ranibizumab and subsequent mitomycin $\mathrm{C}$ augmented trabeculectomy in neovascular glaucoma. J Glaucoma. 2014;23(7):437-40.

27. Kitnarong N, Sriyakul C, Chinwattanakul S. A Prospective Study to Evaluate Intravitreous Ranibizumab as Adjunctive Treatment for Trabeculectomy in Neovascular Glaucoma. Ophthalmol Ther. 2015;4(1):33-41.

28. Li XJ, Yang XP, Li QM, Wang YY, Lyu XB. Ranibizumab Plus Combined Surgery for Treatment of Neovascular Glaucoma with Vitreous Hemorrhage. Chin Med J (Engl). 2015;128(15):2078-83.

29. Luke J, Nassar K, Luke M, Grisanti S. Ranibizumab as adjuvant in the treatment of rubeosis iridis and neovascular glaucoma-results from a prospective interventional case series. Graefes Arch Clin Exp Ophthalmol. 2013;251(10):2403-13.

30. Desai RU, Singh K, Lin SC. Intravitreal ranibizumab as an adjunct for Ahmed valve surgery in open-angle glaucoma: a pilot study. Clin Experiment Ophthalmol. 2013;41(2):155-8.

\section{Submit your next manuscript to BioMed Central and we will help you at every step:}

- We accept pre-submission inquiries

- Our selector tool helps you to find the most relevant journal

- We provide round the clock customer support

- Convenient online submission

- Thorough peer review

- Inclusion in PubMed and all major indexing services

- Maximum visibility for your research

Submit your manuscript at www.biomedcentral.com/submit
C) Biomed Central 